\title{
DIVERSIDADE ENTRE DOCENTES DAS INSTITUIÇÕES DE EDUCAÇÃO SUPERIOR BRASILEIRAS
}

\section{Diversity among professors of brazilian higher education institutions}

\author{
Fabíola Marinho Costa - Universidade Federal do Recôncavo da Bahia/Brasil \\ Roberval Passos de Oliveira - Universidade Federal do Recôncavo da Bahia/Brasil \\ Everson Cristiano de Abreu Meireles - Universidade Federal do Recôncavo da Bahia/Brasil \\ Luciana Alaíde Alves Santana -Universidade Federal do Recôncavo da Bahia/Brasil
}

\begin{abstract}
RESUMO: A diversidade no trabalho pode ser entendida como a representação de pessoas com diferentes identidades grupais, levando a diferentes formas de pensar e agir frente ao trabalho e às organizações. O presente estudo objetivou caracterizar docentes de Instituições de Educação Superior (IES) brasileiras no que se refere a diferentes grupos de identidade (gênero, raça e deficiência). Trata-se de um estudo que utilizou dados secundários do Censo da Educação Superior de 2015, referentes a docentes. Os dados foram tratados mediante o uso de um pacote estatístico, realizando-se análises descritivas. Observou-se que a maioria dos docentes $(57,3 \%)$ trabalhava em instituições privadas. Dentre as instituições públicas, a maior parte estava vinculada a instituições federais $(27,2 \%)$. Em relação a gênero, 54,6\% eram Homens e 45,4\% Mulheres. Sobre grupo racial, identificou-se uma maioria de docentes Brancos $(75,0 \%)$, em comparação ao número de Negros $(23,4 \%)$. O percentual de Pessoas com Deficiência mostrou-se muito mais baixo $(0,4 \%)$ entre docentes do que na população brasileira $(31,4 \%)$. Diante desses resultados, é possível perceber, entre docentes de IES, uma sub-representação de Mulheres, Pessoas Negras e Pessoas com Deficiência. Entende-se que levantamentos acerca de como grupos são representados e atuam em IES mostram-se relevantes para elaboração de políticas e práticas de diversidade e inclusão, que envolvem promover representatividade numérica e valorização dos diversos grupos.
\end{abstract}

Palavras-chave: Diversidade. Docentes. Instituições de Ensino Superior.

ABSTRACT: Diversity at work can be understood as the representation of people with different group identities, leading to different ways of thinking and acting towards work and organizations. The present study aimed to characterize professors from Brazilian Higher Education Institutions (HEI) regarding different identity groups (gender, race and disability). This study used secondary data from the 2015 Higher Education Census for professors. Data were processed using a statistical package and descriptive analyzes were performed. Most professors $(57.3 \%)$ worked in private institutions. Among public institutions, most ones were linked to federal institutions (27.2\%). Regarding gender, $54.6 \%$ were men and $45.4 \%$ women. Regarding racial group, a majority of white teachers $(75.0 \%)$ were identified, compared to the number of blacks $(23.4 \%)$. The percentage of people with disabilities was much lower $(0.4 \%)$ among professors than in the brazilian population (31.4\%). In accord of these results, it is possible to notice, among HEI professors, an under representation of Women, Black People and People with Disabilities. Surveys about how groups are represented and act in HEI are relevant to elaboration of diversity and inclusion policies and practices, which involves promoting numerical representativeness and valuing the various groups.

Keywords: Diversity. Teacher. Higher Education Institutions.

Educação, Psicologia e Interfaces, Volume 3, Dossiê Inclusão e Diversidade, p. 67-82, 2019. ISSN: 2594-5343. DOI: https://doi.org/10.37444/issn-2594-5343.v3i4.150 


\section{INTRODUÇÃO}

O Brasil é uma referência mundial de um grupo cultural diverso, embora o campo de estudos em diversidade organizacional ainda seja muito incipiente e as práticas voltadas para a diversidade e inclusão na área de gestão de pessoas ainda sejam raras (TORRES; PÉREZNEBRA, 2014). Apesar do contexto cultural diversificado, em que atuam as organizações brasileiras, o recente tema diversidade surge em subsidiárias de empresas americanas por pressão da matriz e, em seguida, ligado à necessidade de criar vantagens competitivas, desenvolvendo competências diversas (FLEURY, 2000). A literatura no campo da diversidade é predominantemente estadunidense e, em menor escala, canadense, tendo origem a partir de dispositivos compulsórios (determinados pelo governo), em face da necessidade de lidar com fortes questões raciais e pressões crescentes de grupos étnicos e de minorias (HANASHIRO, 2005). Grande parte da discussão sobre diversidade está ligada a classes de pessoas estabelecidas por meio de categorias de minoria, que visam a focalizar grupos para ajudar a estabelecer um sistema social mais justo e equitativo, e são construídas mediante discursos formados politicamente (POPKEWITZ; LINDBLAD, 2001). No presente trabalho, serão consideradas "minorias" ou pessoas "diversas" aquelas pertencentes a grupos tradicionalmente sub-representados no mundo do trabalho em termos de poder, prestígio e status.

As primeiras publicações científicas nacionais sobre diversidade no trabalho datam do início dos anos 1990, enfatizando a necessidade de estudos que acompanhassem a mudança da força de trabalho brasileira (HANASHIRO; TORRES, 2010). Estudos sobre diversidade, realizados em contexto brasileiro, revelam três importantes lacunas no âmbito dos estudos sobre organizações, que resultam da pouca ênfase que as pesquisas têm dado: (1) aos diversos tipos de minorias nas organizações; (b) às especificidades do contexto organizacional brasileiro diante dessa diversidade; e (c) à efetividade das políticas de promoção da diversidade nas organizações brasileiras (ROSA, 2014).

No mundo do trabalho, diversidade significa dizer que pessoas diferentes ocupam cargos diferentes e pode ser compreendida tanto como demográfica, como cognitiva, relativa às habilidades e aos valores (TORRES; PÉREZ-NEBRA, 2014). As diferenças demográficas são mais estáveis, mais difíceis de serem modificadas e estão relacionadas a fatores como

Educação, Psicologia e Interfaces, Volume 3, Dossiê Inclusão e Diversidade, p. 67-82, 2019. 
gênero, sexualidade, raça, etnia, habilidade física, idade, religião, língua, história cultural, sendo que em vários contextos esses fatores estão relacionados.

A diversidade, como composição numérica, refere-se à composição da força de trabalho, e, para alcançar um equilíbrio dinâmico, é importante fomentar a inserção de atores sociais de identidades variadas no contexto organizacional, o que implica em estimular a contratação de membros de grupos mais desprivilegiados e o seu desenvolvimento na organização de maneira que ocupem as mais variadas posições (VASCONCELOS; VASCONCELOS; MASCARENHAS, 2004). Apreendida em sua dimensão cultural, a diversidade é associada a movimentos sociais e articula-se à exigência de reconhecimento, na esfera pública e política, de grupos definidos como "minoritários" e "subalternos" que, no Brasil, partiu de alguns setores dos movimentos feminista, negro, indígena e de pessoas com deficiência (MOEHLECKE, 2009).

Ao estudar o perfil social, racial e de gênero nas 500 maiores empresas do Brasil, em todos os níveis hierárquicos, o Instituto Ethos de Empresas e Responsabilidade Social identificou um cenário de grandes desigualdades. Na pesquisa de 2016, porém, destacaram-se o aumento significativo da participação de Mulheres $^{1}$ em níveis gerenciais e a presença majoritária de Pessoas Negras entre trainees e aprendizes, inserção essa atribuída às políticas públicas na área de educação implementadas nos anos anteriores (ETHOS, 2016). Por outro lado, a maioria das empresas participantes desta pesquisa não possuia ações afirmativas para incentivar a presença de Mulheres e Pessoas Negras em seus quadros de pessoal, nem desenvolvia políticas visando a promoção da igualdade de oportunidades entre Homens e Mulheres ou entre Pessoas Negras e Pessoas Brancas. Quando possuiam alguma prática, eram ações pontuais e não políticas com metas e ações planejadas. Ao analisar as pessoas que trabalhavam em médias e grandes empresas no Brasil e as posições ocupadas por elas, observou-se que alguns grupos sociais estavam mais bem representados e que as organizações pareciam preferir, para os postos de comando, um tipo específico: homem branco, em idade adulta, cisgênero, aparentemente heterossexual e sem deficiência visível (CONCEIÇÃO, 2016).

A gestão da diversidade e inclusão é um processo inevitável e irreversível diante das mudanças demográficas e das exigências do mundo do trabalho, cumpre com a responsabilidade social e com a legislação e pode trazer benefícios financeiros (TORRES; 
PÉREZ-NEBRA, 2014). Essa gestão tem início com um diagnóstico acerca da heterogeneidade demográfica. A demografia organizacional investiga a representação de grupos de identidade como importante fator do ambiente organizacional, que pode influenciar a construção de significados associados aos grupos de identidade. No entanto, a gestão vai além da demografia organizacional e envolve criar uma cultura de inclusão, que se refere tanto à representação numérica dos grupos quanto à condição em que estes podem ser autênticos e participar da organização de forma efetiva (PRESOTTI, 2011).

Algumas empresas brasileiras realizam práticas de gestão da diversidade como: capacitação de gestores e equipes nos temas da diversidade e da igualdade de oportunidades; manutenção de canais para receber queixas em relação a problemas como assédio moral e preconceitos; cumprimento da legislação, como a que prevê cotas para pessoas com deficiência; promoção de ações direcionadas a grupos historicamente discriminados no mundo do trabalho, como Mulheres, Pessoas Negras, Pessoas Com Deficiência e o público LGBT (sigla para designar o público composto por lésbicas, gays, travestis, transexuais e transgêneros - identifica uma minoria da população no que diz respeito à sua orientação sexual e identidade de gênero); cadastramento do dado como cor/raça nos processos de recrutamento e seleção, bem como nas oportunidades de treinamento, de ascensão e de mentoring (ETHOS, 2016). Ademais, apresentam-se como uma importante política de diversidade os grupos de suporte, que constituem ações coletivas por meio das quais grupos minoritários e/ou historicamente discriminados e excluídos das posições de maior poder, prestígio e remuneração nas organizações buscam dar apoio emocional e promover a carreira dos seus membros (BRUNSTEIN; JAIME, 2009).

Diante desse cenário, o presente estudo objetivou caracterizar docentes de Instituições de Ensino Superior (IES) brasileiras no que se refere a diferentes grupos de identidade, nos quais membros compartilham características biológicas e/ou sociais comuns, a exemplo de gênero/sexo, raça/etnia e deficiência. Dada a histórica exclusão de Mulheres, Pessoas Negras e Pessoas Com Deficiência, busca-se investigar como esses trabalhadores se encontram representados como docentes nas IES. Esse objetivo contribui para o que propõe Rosa (2014), no que se refere às relações raciais, ao defender reflexões sobre a diversidade na organização do espaço acadêmico.

Educação, Psicologia e Interfaces, Volume 3, Dossiê Inclusão e Diversidade, p. 67-82, 2019. ISSN: 2594-5343. DOI: https://doi.org/10.37444/issn-2594-5343.v3i4.150 


\section{MATERIAL E MÉTODO}

Trata-se de um estudo que se utilizou de dados secundários, os quais foram produzidos a partir de microdados públicos, disponibilizados pelo Instituto Nacional de Estudos e Pesquisas Educacionais Anísio Teixeira (Inep), que reúnem informações sobre o Censo da Educação Superior. Esta coleta de informações é realizada anualmente pelo Inep junto às IES que ofertam cursos de graduação e sequencias de formação específica.

A coleta de dados ocorre a partir do preenchimento dos questionários, por parte das IES e por importação de dados do Sistema e-MEC. Durante o período de preenchimento do questionário, os pesquisadores institucionais podem fazer alterações ou inclusões necessárias nos dados das respectivas instituições. Trata-se de uma base produzida pelas IES e submetida a um sistema de validação concebido pelo Inep.

O recorte temporal adotado no presente estudo foi o ano de 2015. Foram analisados os dados de 107 IFES distribuídas nas cinco regiões do país, sendo: 63 Universidades Federais, 38 Institutos, 04 Faculdades e 02 Centros. Com base nos dados do Censo da Educação Superior, havia, no ano de 2015, aproximadamente, 388 mil docentes nas IES brasileiras. A maioria dos docentes $(57,3 \%)$ trabalhava em instituições privadas. Dentre as instituições públicas (federal, estadual e municipal), a maior parte estava vinculada a instituições federais $(27,2 \%)$.

Em relação à idade, grande parte dos docentes de IES encontrava-se na faixa entre 36 e 50 anos (45,7\%), além de haver uma parcela de docentes mais jovens (26,1\% com até 35 anos) e aqueles com 51 anos ou mais (28,2\%). Quanto à escolaridade, 98,3\% dos docentes possuíam pós-graduação, dos quais 36,6\% doutorado e 39,7\% mestrado. Pouco mais da metade dos docentes $(50,1 \%)$ trabalhava em tempo integral nas IES, sendo $29,0 \%$ com dedicação exclusiva. Por outro lado, $49,9 \%$ eram horistas $(23,1 \%)$ ou trabalhavam em tempo parcial $(26,8 \%)$.

Os dados foram exportados para um software estatístico. Para analisar a representação dos diferentes grupos na docência das IES, foi utilizada como padrão de referência a população com faixa etária similar àquela em que estão os docentes (população brasileira a partir de 20 anos), por meio dos dados da Pesquisa Nacional por Amostra de Domicílios (PNAD) 2015 (IBGE, 2015). 


\section{RESULTADOS E DISCUSSÃO}

Entre os docentes das IES, 211.889 eram Homens (54,6\%) e 176.115 Mulheres $(45,4 \%)$. Ao utilizar como padrão de referência a população com mesma faixa etária, conforme a PNAD 2015 (Homens = 47,4\%; Mulheres = 52,6\%) (IBGE, 2015), observa-se que, entre docentes de IES, a razão entre Homens e Mulheres era distinta: as Mulheres se encontravam em uma proporção menor. As Mulheres, também, estão sub-representadas em um estudo sobre o serviço público civil (OSÓRIO, 2006) e na pesquisa com as 500 maiores empresas do Brasil (ETHOS, 2016), conforme a qual as Mulheres enfrentam, além da desigualdade em relação aos Homens, um afunilamento hierárquico com menor inclusão delas à medida que aumentam as atribuições de comando.

Tem se fortalecido a compreensão de que as condições e causas da exclusão social são diferentes para Mulheres e Homens, Pessoas Negras e Pessoas Brancas e que as dimensões de gênero e raça são fatores que determinam, em grande parte, as possibilidades de acesso ao emprego, assim como as condições em que ele é exercido (OSÓRIO, 2006). Nesse sentido, as desigualdades e a discriminação relacionadas a gênero, raça, deficiências são eixos estruturantes dos padrões de exclusão social no Brasil. Dentre os desafios, apresenta-se a necessidade de diagnósticos do nível e das características da diversidade racial, de gênero e envolvendo Pessoas Com Deficiência, o que envolve o levantamento demográfico dos trabalhadores inseridos no mundo o trabalho.

A presente investigação buscou, também, por meios indiretos, verificar se Mulheres têm as mesmas oportunidades de desenvolvimento no trabalho docente, utilizando como referência o grupo dos Homens. Para tanto, investigou-se dois diferentes aspectos da carreira docente: a participação em atividades de gestão e o recebimento de bolsa de pesquisa. Esses aspectos, em geral, representam um acréscimo na remuneração do docente, assim como um lugar de maior poder e status nas IES. Dos docentes ativos em IES, no ano de 2015, 22,9\% ocupavam cargos de gestão. Observa-se que, entre docentes Homens, 22,8\% ocupavam cargos, enquanto 23,1\% das Mulheres estavam envolvidas com esse tipo de atividade acadêmica (Figura 1). Assim, percebe-se que os dois grupos apresentavam percentuais muito próximos de ocupação de cargos. Quando tomados como referência todos os docentes e

Educação, Psicologia e Interfaces, Volume 3, Dossiê Inclusão e Diversidade, p. 67-82, 2019. ISSN: 2594-5343. DOI: https://doi.org/10.37444/issn-2594-5343.v3i4.150 
comparados esses dois grupos, percebe-se que 12,4\% dos Homens e 10,5\% das Mulheres participavam de atividades de gestão.

Homens X gestão

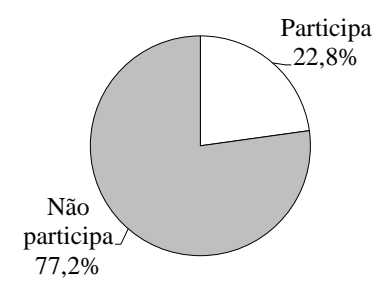

Homens e Mulheres X gestão

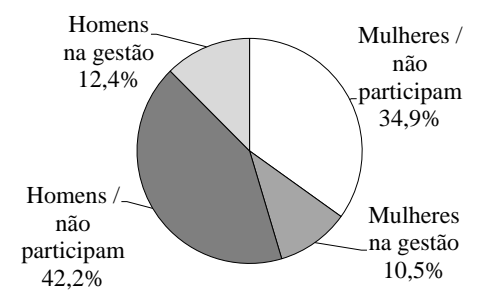

Mulheres X gestão

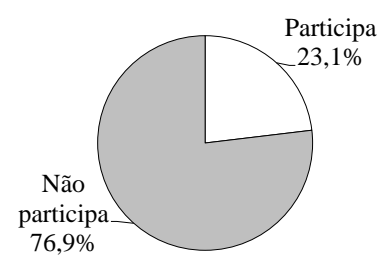

Figura 1. Porcentagem de Homens e Mulheres entre docentes nas IES que participam de atividade de gestão. Fonte: Censo da Educação Superior 2015.

Em análise dos dados produzidos pela PNAD, nos anos de 2004 a 2014, evidencia-se o crescimento do protagonismo feminino no mundo do trabalho, a despeito das persistentes desigualdades salariais, com destaque para a situação das Mulheres Negras que, ainda que muito distante dos demais segmentos identificados segundo o gênero e raça/cor, representam a força do efeito combinado dos sistemas discriminatórios de gênero, raça e classe (PINHEIRO; LIMA JUNIOR; FONTOURA; SILVA, 2016).

No ano de 2015, 15,5\% dos docentes ativos em IES recebiam bolsa de pesquisa. Quanto ao recebimento de bolsa, percebe-se que os dois grupos (Homens 15,9\% e Mulheres $15,0 \%$ ) também apresentavam percentuais muito próximos (Figura 2). Quando tomados como referência todos os docentes e comparados esses dois grupos, percebe-se que 8,5\% dos Homens e 6,9\% das Mulheres recebiam bolsa de pesquisa. A partir desses resultados, é possível obervar que, apesar de sub-representadas, enquanto docentes de IES, quando conquistam essa inserção, as Mulheres vêm conseguindo ocupar lugares de poder e status, por meio da participação em atividades de gestão e do recebimento de bolsas de pesquisa.

Homens X bolsa

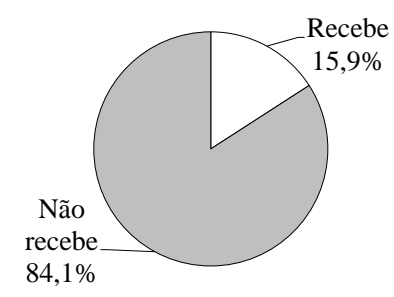

Homens e Mulheres X bolsa

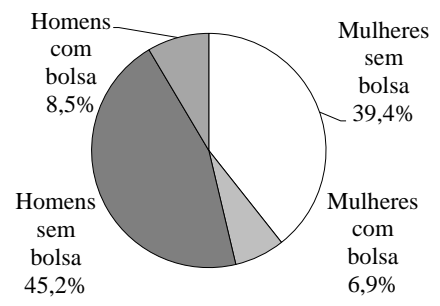

Mulheres X bolsa

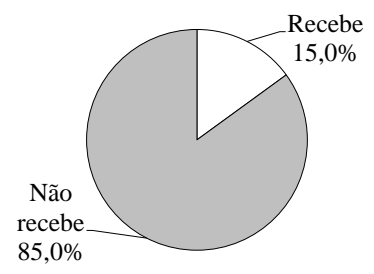

Figura 2. Porcentagem de Homens e Mulheres entre docentes nas IES que recebem bolsa de pesquisa. Fonte: Censo da Educação Superior 2015.

Educação, Psicologia e Interfaces, Volume 3, Dossiê Inclusão e Diversidade, p. 67-82, 2019.

ISSN: 2594-5343. DOI: https://doi.org/10.37444/issn-2594-5343.v3i4.150 
No mundo do trabalho, as Mulheres são tratadas como trabalhadoras de segunda categoria, pois recebem salários inferiores aos dos Homens (70\% da massa salarial obtida pelos Homens) e se deparam com o "Teto de Vidro", responsável pelo escasseamento da presença feminina nos cargos superiores, ainda que tenham as competências necessárias para tanto (MORENO, 2016). O "Teto de Vidro" é uma barreira sutil e transparente, mas suficientemente forte para bloquear a ascensão das Mulheres a níveis hierárquicos mais altos, limitando a progressão, com base no gênero e não na qualificação, fenômeno que ocorre tanto no setor privado como no público (VAZ, 2013).

Para além dessas questões, observa-se que, no meio acadêmico, as Mulheres vivenciam outra condição desfavorável: menor acesso a posições de prestígio nas IES, nos comitês científicos e nas academias de ciências (VAZ, 2013). Esse processo cumulativo de desvantagens dificulta a obtenção de recursos para pesquisa, o que impacta diretamente no desempenho acadêmico, limitando suas possibilidades profissionais. Apesar disso, entende-se que uma representação adequada das Mulheres nas IES, na qual a proporção seja igual ou muito próxima à população brasileira, poderá contribuir com a minimização dessas desigualdades no que se refere à presença feminina em lugares de maior poder e status nas IES.

Para a análise da composição racial, foram agregadas Pessoas Pretas e Pessoas Pardas para a formação do grupo de Pessoas Negras. Assim como no ensaio de Rosa (2014), o presente trabalho foca as relações raciais envolvendo Pessoas Negras e Pessoas Brancas, em virtude de os estudos brasileiros sobre raça terem se ocupado, principalmente, da questão das Pessoas Negras e dos desdobramentos históricos do período escravocrata para as relações raciais. Na faixa etária considerada, havia, no Brasil, um percentual maior de Pessoas Negras $(53,9 \%)$ do que de Pessoas Brancas (45,2\%) (IBGE, 2015). Entretanto, nas IES, identifica-se uma ampla maioria de docentes Brancos $(75,0 \%)$, em comparação ao número de docentes Negros $(23,4 \%)$. Assim, pode-se identificar uma sub-representação de Pessoas Negras entre docentes das IES brasileiras. Nesse mesmo sentido, pode-se afirmar que havia uma sobrerepresentação de Pessoas Brancas entre docentes das IES brasileiras. Rosa (2014) traz reflexões sobre implicações de uma academia em que a presença de pesquisadores Negros é notadamente baixa, questionando o tipo de espaço que estamos reproduzindo na universidade, que torna a academia tão branca diante de uma sociedade tão colorida.

Educação, Psicologia e Interfaces, Volume 3, Dossiê Inclusão e Diversidade, p. 67-82, 2019. 
A composição racial na docência do ensino superior brasileiro pode ser atribuída a um problema estrutural relacionado à discriminação institucional, anterior ao momento da entrada nas IES, que produz desvantagens educacionais da população negra. Assim como em outros estudos (OSÓRIO, 2006; ETHOS, 2016), as Pessoas Negras estão, como as Mulheres, em situação de desigualdade, sub-representação e afunilamento hierárquico, que os exclui dos postos mais elevados da escala hierárquica, sendo tal exclusão mais acentuada do que a das Mulheres. As organizações, portanto, podem ser pensadas como um microcosmo social, que reproduz uma série de fenômenos tradicionalmente presentes na sociedade brasileira, entre os quais as relações raciais (ROSA, 2014).

Assim como na análise de gênero, a presente investigação buscou verificar se Pessoas Negras têm as mesmas oportunidades de desenvolvimento no trabalho docente, utilizando como referência o grupo de Pessoas Brancas, e investigando a participação em atividades de gestão e o recebimento de bolsa de pesquisa. Dos docentes ativos em IES, no ano de 2015, $22,9 \%$ ocupavam cargos de gestão. Dentre os docentes que participavam de atividades de gestão, 78,7\% eram Brancos (Figura 3).

Raça x gestão

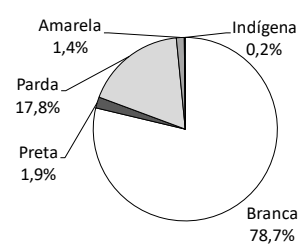

Brancos X gestão

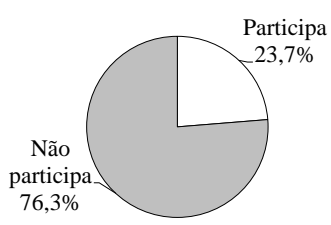

Brancos e Negros X gestão

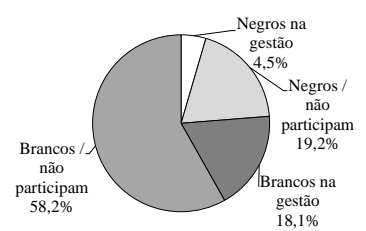

Negros X gestão

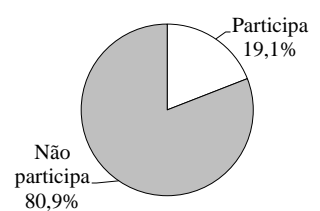

Figura 3. Porcentagem de Pessoas Brancas, Negras (Pretas ou Pardas), Amarelas e Indígenas entre docentes nas IES que participam de atividade de gestão. Fonte: Censo da Educação Superior 2015.

Observa-se que, entre docentes Brancos, 23,7\% estavam envolvidos com esse tipo de atividade acadêmica, enquanto um percentual menor de docentes Negros (19,1\%) ocupavam cargos (Figura 4). Quando tomados como referência todos os docentes dos dois grupos e comparados esses, percebe-se que participavam de atividades de gestão $18,1 \%$ de docentes Brancos e apenas 4,5\% de docentes Negros.

Dos docentes ativos em IES, no ano de 2015, 15,5\% recebiam bolsa de pesquisa. Dentre os docentes que recebiam bolsa de pesquisa, 79,8\% eram Pessoas Brancas (Figura 4). 


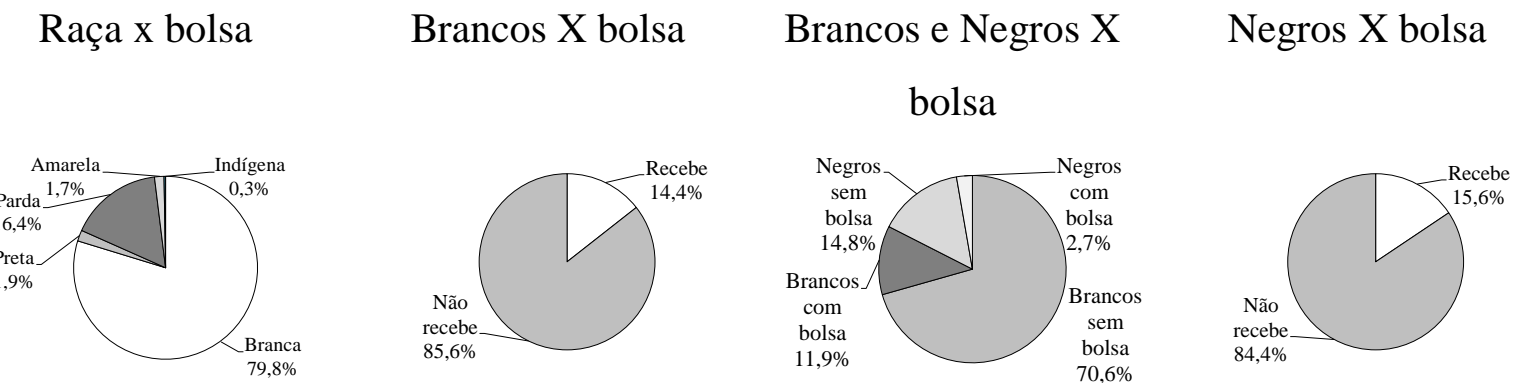

Figura 4. Porcentagem de Pessoas Brancas, Negras (Pretas ou Pardas), Amarelas e Indígenas entre docentes nas IES que recebem bolsa de pesquisa. Fonte: Censo da Educação Superior 2015 .

No que se refere ao recebimento de bolsa de pesquisa, percebe-se que os dois grupos (Pessoas Brancas 14,4\% e Pessoas Negras 15,6\%) apresentavam percentuais próximos (Figura 8). Quando tomados como referência todos os docentes dos dois grupos e comparados esses, percebe-se que 11,9\% de Pessoas Brancas e apenas 2,7\% de Pessoas Negras recebiam bolsa de pesquisa. Diante desse cenário, reitera-se a necessidade de debater a valorização da diversidade étnico racial para compreender as desigualdades estruturantes do Brasil. Ademais, o desenvolvimento de políticas de ações afirmativas, com foco na equidade racial, proporcionará às organizações que se pareçam mais com o país e ganhem em inovação e complementaridade (SANTOS, 2016).

Em relação às Pessoas Com Deficiência, no Brasil, segundo dados divulgados pelo Instituto Brasileiro de Geografia e Estatística (IBGE, 2010) e relativos ao Censo Demográfico de 2010, existiam 40,1 milhões, que tinham 20 anos ou mais de idade, representando 31,4\% da população com essa faixa etária. Desse total, apenas 49,1\% estavam ocupadas. Entre docentes nas IES, o percentual mostra-se muito mais baixo: 0,4\%. Nesse grupo ocupacional, os tipos de deficiência mais frequentes foram: deficiência física $(43,6 \%)$, baixa visão $(26,1 \%)$ e deficiência auditiva $(19,3 \%)$.

No país, há ações afirmativas para o grupo das Pessoas Com Deficiência, que estabelecem reservas de vagas vinculadas ao sistema de ingresso nas organizações. Embora a existência das disposições legais não garanta o cumprimento da lei e a fiscalização seja necessária, a existência da legislação teve impactos positivos e mensuráveis sobre a empregabilidade das Pessoas Com Deficiência (OSÓRIO, 2006). Entretanto, como é possível

Educação, Psicologia e Interfaces, Volume 3, Dossiê Inclusão e Diversidade, p. 67-82, 2019. 
observar pelos resultados desse estudo, ainda existe uma sub-representação de Pessoas Com Deficiência entre docentes de IES brasileiras.

Além das repercussões positivas para os Trabalhadores Com Deficiência e suas famílias, a inclusão dessas pessoas no mundo do trabalho traz resultados positivos também para a empresa (colabora para melhorar o clima, a produtividade, a sustentabilidade e a imagem da organização) e para a sociedade (mais pessoas exercendo sua cidadania, desenvolvendo seu potencial, tendo acesso ao consumo e cumprindo suas obrigações fiscais) (GIL, 2016). A inserção de Pessoas Com Deficiência, e, mais amplamente, a diversidade no trabalho, são desafios que mostram a necessidade de combinar o incentivo ao engajamento voluntário das organizações em temas complexos com mecanismos de controle e punição sobre elas, assim como são fundamentais as percepções subjetivas dos diversos envolvidos e os espaços de diálogo, reflexividade e negociação entre eles.

Dentre as políticas ou ações afirmativas voltadas para grupos como Mulheres, Pessoas Negras e Pessoas Com Deficiência podem ser relacionadas: programas especiais para a contratação de pessoas desses grupos; programas de capacitação profissional que visem melhorar a qualificação de pessoas desses grupos para assumir postos não ocupados tradicionalmente por elas ou postos de maior nível hierárquico; metas e programas para a redução das desigualdades salariais entre Mulheres e Homens / Pessoas Negras e Pessoas Não Negras / Pessoas Com Deficiência e Pessoas Sem Deficiência; metas para ampliar a presença das Mulheres / Pessoas Negras em cargos de direção e gerência; e, para as Mulheres, adoção de medidas de conciliação entre trabalho, família e vida pessoal (ETHOS, 2016).

\section{CONSIDERAÇÕES FINAIS}

Foi possível perceber que a representação de grupos relacionados a gênero, raça e deficiência, entre docentes de IES, apresentou-se distinta da configuração da população brasileira: ao considerar esses grupos, a população brasileira não tem sua diversidade demográfica representada nas IES, demonstrando uma sub-representação de Mulheres, Pessoas Negras e Pessoas Com Deficiência. É, portanto, ao grupo dos Homens, das Pessoas Brancas e das Pessoas Sem Deficiência que a docência nas IES apresenta maior permeabilidade. A presente caracterização dos docentes permite ampliar reflexões sobre a 
institucionalização da exclusão social e discriminação de grupos sociais minoritários no âmbito organizacional das IES brasileiras.

Além do menor acesso à ocupação de professor de ensino superior, esses grupos sociais recebem um tratamento diferenciado em relação a outros grupos em posição equivalente, como, por exemplo, menores possibilidades de participar de atividades de gestão ou receber bolsas de pesquisa. Nesse caso, observam-se indícios de discriminação no que se refere à diversidade, por meio da demografia organizacional. Outra forma de discriminação que pode ocorrer em relação à inclusão desses trabalhadores no contexto de trabalho é a institucional. Essa discriminação consiste em práticas sutis que influenciam o comportamento quotidiano dos grupos sociais e criam desigualdades entre pessoas, a partir das bases de distinção que sejam localmente importantes como raça, etnia, gênero, religião, nacionalidade. Diante das desigualdades sociais de caráter estrutural que se refletem no mundo do trabalho no Brasil, a promoção da diversidade e da equidade apresenta-se como necessária para garantir um desenvolvimento econômico com desenvolvimento social.

Como um limite do presente estudo, mostra-se importante pontuar os altos percentuais de “dados não declarados" em variáveis do Censo da Educação Superior. Essa questão dificulta a caracterização de um perfil mais fidedigno de docentes das IES brasileiras e demanda do Inep o fomento de mecanismos para um preenchimento adequado desses dados.

Além de investigar outros grupos de identidade (relativos à idade e orientação sexual, e.g.), futuros estudos podem se dedicar à interação entre diferentes dimensões de diversidade (e.g., Mulheres Negras), visto que a pertença simultânea a mais de um grupo vulnerável pode ampliar a carga das discriminações. Ademais, novos estudos podem considerar as diferenças regionais de composição da população no que se refere aos grupos investigados.

Entende-se que levantamentos acerca de como os grupos identitários são representados e atuam nas IES brasileiras (demografia organizacional) mostram-se relevantes para elaboração de políticas e práticas de diversidade e inclusão, que envolvem tanto promover uma representatividade numérica, como a valorização e a participação dos diversos grupos, visto que o ingresso em IES não implica igualdade de tratamento a docentes com diferentes identidades grupais. Essas políticas e práticas, portanto, além de se centrar na garantia da representatividade dos diversos grupos, devem buscar a modificação dos papéis socialmente

Educação, Psicologia e Interfaces, Volume 3, Dossiê Inclusão e Diversidade, p. 67-82, 2019. 
estabelecidos, envolvendo tanto aqueles que incluem/excluem quanto aqueles que são incluídos/excluídos, uma vez que a experiência de inclusão tem que ser coletiva.

Defende-se, portanto, que as IES se beneficiariam com reflexões acerca de políticas e práticas para valorizar a diversidade e promover a inclusão no ambiente de trabalho. É importante trabalhar e denunciar o imaginário popular de uma sociedade livre de preconceitos, cujo acesso às posições no sistema educacional e no mundo do trabalho é aberto a todos, em um país como o Brasil, com uma sociedade heterogênea e com muitas desigualdades sociais. Afinal, se pessoas com diferentes identidades grupais apresentam diferentes formas de pensar, sentir e agir frente ao trabalho, como promover uma educação para a diversidade e inclusão sem diversidade e inclusão entre educadores?

\section{Notas de rodapé}

\footnotetext{
${ }^{1}$ Adotamos a prática de apresentação dos termos que definem os grupos de identidade com iniciais maiúsculas para ressaltar e reconhecer a significância cultural dessas identidades grupais.
}

\section{REFERÊNCIAS BIBLIOGRÁFICAS}

BRUNSTEIN, J.; JAIME, P. Da estratégia individual à ação coletiva: grupos de suporte e gênero no contexto da gestão da diversidade. RAE-eletrônica, São Paulo, v. 8, n. 2, 2009. Disponível em <http://www.scielo.br/scielo.php?script=sci_arttext\&pid=S167656482009000200004\&lng=en\&nrm=iso $>$. Acesso em: 10 Out. 2017. http://dx.doi.org/10.1590/S1676-56482009000200004.

CONCEIÇÃO, E. B. Monitoramento das ações ainda é incipiente. In: ETHOS. Instituto Ethos de Empresas e Responsabilidade Social. Perfil Social, Racial e de Gênero das 500 Maiores Empresas do Brasil e Suas Ações Afirmativas. São Paulo, 2016, p. 63-65. Disponível em http://www.onumulheres.org.br/wpcontent/uploads/2016/04/Perfil_social_racial_genero_500empresas.pdf. Acesso em 07 Jun. 2019.

ETHOS. Instituto Ethos de Empresas e Responsabilidade Social. Perfil Social, Racial e de Gênero das 500 Maiores Empresas do Brasil e Suas Ações Afirmativas. São Paulo, 2016. Disponível em http://www.onumulheres.org.br/wpcontent/uploads/2016/04/Perfil_social_racial_genero_500empresas.pdf. Acesso em 07 Jun. 2019.

FLEURY, M. T. L. Gerenciando a diversidade cultural: experiências de empresas Brasileiras. RAE-Revista de Administração de Empresas, São Paulo, v. 40, n. 3, p. 18-25, 2000. Disponível em <http://www.scielo.br/scielo.php?script=sci_arttext\&pid=S0034$75902000000300003 \& \operatorname{lng}=e n \& n r m=i s o>$. Acesso em 23 Jun. 2017. http://dx.doi.org/10.1590/S0034-75902000000300003.

Educação, Psicologia e Interfaces, Volume 3, Dossiê Inclusão e Diversidade, p. 67-82, 2019. ISSN: 2594-5343. DOI: https://doi.org/10.37444/issn-2594-5343.v3i4.150 
GIL, M. Inclusão estimula a criatividade. In: ETHOS. Instituto Ethos de Empresas e Responsabilidade Social. Perfil Social, Racial e de Gênero das 500 Maiores Empresas do Brasil e Suas Ações Afirmativas. São Paulo, 2016, p. 32-33. Disponível em http://www.onumulheres.org.br/wpcontent/uploads/2016/04/Perfil_social_racial_genero_500empresas.pdf. Acesso em 07 Jun. 2019.

HANASHIRO, D. M. M.; CARVALHO, S. G. Diversidade cultural: panorama atual e reflexões para a realidade brasileira. Revista Eletrônica de Administração, v. 11, n. 5, p. 121, 2005. Disponível em https://seer.ufrgs.br/read/article/view/40623. Acesso em 24 Jun. 2017.

HANASHIRO, D. M. M.; TORRES, C. V. Introdução. RAM, Revista de Administração Mackenzie (Online), v.11, n.3, p.2-5, 2010. Disponível em <http://www.scielo.br/scielo.php?script=sci_arttext\&pid=S167869712010000300002\&lng=pt\&nrm=iso>. Acesso em 05 Jul. 2017. http://dx.doi.org/10.1590/S1678-69712010000300002.

INSTITUTO BRASILEIRO DE GEOGRAFIA E ESTATÍSTICA (IBGE). Censo

Demográfico 2010. [online] Disponível em www.ibge.gov.br. Acesso em 20 Out. 2017.

INSTITUTO BRASILEIRO DE GEOGRAFIA E ESTATÍSTICA (IBGE). PNAD - Pesquisa Nacional por Amostra de Domicílios, 2015. [online] Disponível em www.ibge.gov.br. Acesso em 20 Out. 2017.

MOEHLECKE, S. As políticas de diversidade na educação no governo Lula. Cadernos de Pesquisa, São Paulo, v. 39, n. 137, p. 461-487, 2009. Diponível em <http://www.scielo.br/scielo.php?script=sci_arttext\&pid=S010015742009000200008\&lng=en\&nrm=iso>. Acesso em 05 Jul. 2018. http://dx.doi.org/10.1590/S0100-15742009000200008.

MORENO, R. O sexismo custa caro. In: ETHOS. Instituto Ethos de Empresas e Responsabilidade Social. Perfil Social, Racial e de Gênero das 500 Maiores Empresas do Brasil e Suas Ações Afirmativas. São Paulo, 2016, p. 20-21.

OSÓRIO, R. G. Desigualdades raciais e de gênero no serviço público civil. Brasília: OIT Secretaria Internacional do Trabalho, Cadernos GRPE, n. 2, 2006.

PINHEIRO, L. S.; LIMA JUNIOR, A. T.; FONTOURA, N. O.; SILVA, R. Mulheres e trabalho: breve análise do período 2004-2014. Brasília, IPEA - Instituto de Pesquisa Econômica Aplicada, Nota Técnica, 2016. Disponível em http://www.ipea.gov.br/portal/images/stories/PDFs/nota_tecnica/160309_nt_24_mulher_traba lho_marco_2016.pdf. Acesso em 07 Jun. 2019.

POPKEWITZ, T.; LINDBLAD, S. Estatísticas educacionais como um sistema de razão: relações entre governo da educação e inclusão e exclusão sociais. Educação \& Sociedade, Campinas, v. 22, n. 75, p. 111-148, 2001. Disponível em

Educação, Psicologia e Interfaces, Volume 3, Dossiê Inclusão e Diversidade, p. 67-82, 2019. ISSN: 2594-5343. DOI: https://doi.org/10.37444/issn-2594-5343.v3i4.150 
<http://www.scielo.br/scielo.php?script=sci_arttext\&pid=S0101-

$73302001000200008 \& \operatorname{lng}=$ en \&nrm=iso>. Acesso em 05 Jul. 2017.

http://dx.doi.org/10.1590/S0101-73302001000200008.

PRESOTTI, L. Gerenciar a diversidade cultural nas organizações?: caminhos para a inclusão. 2011. 152 f. Dissertação (Mestrado em Psicologia Social, do Trabalho e das Organizações) - Universidade de Brasília, Brasília, 2011. Disponível em

http://repositorio.unb.br/bitstream/10482/10186/1/2011_LuaraPresotti.pdf. Acesso em 07 Jun. 2019.

ROSA, A. R. Relações raciais e estudos organizacionais no Brasil. Revista de Administração Contemporânea, Curitiba, v. 18, n. 3, p. 240-260, 2014. Disponível em http://www.scielo.br/pdf/rac/v18n3/v18n3a02.pdf. Acesso em 20 Ago. 2017.

SANTOS, H. Diversidade é vantagem competitiva. In: ETHOS. Instituto Ethos de Empresas e Responsabilidade Social. Perfil Social, Racial e de Gênero das 500 Maiores Empresas do Brasil e Suas Ações Afirmativas. São Paulo, 2016, p. 67-69.

TORRES, C. V.; PÉREZ-NEBRA, A., R. Diversidade e inclusão nas organizações. In: ZANELLI, J. C.; BORGES-ANDRADE, J. E.; BASTOS, A. V. B. (Orgs.). Psicologia, organizações e trabalho no Brasil. Porto Alegre: Artmed, 2014, p. 526-546.

VASCONCELOS, I. F. G.; VASCONCELOS, F. C.; MASCARENHAS, A. O. Batom, pó de arroz e microchips - o falso paradoxo entre as dimensões masculina e feminina nas organizações e a gestão de pessoas. Organizações \& Sociedade, Salvador, v. 11, n. 31, p. 119-134, 2004. Disponivel em <http://www.scielo.br/scielo.php?script=sci_arttext\&pid=S198492302004000300007\&lng=en\&nrm=iso>. Acesso em 05 Aug. 2017.

VAZ, D. V. O teto de vidro nas organizações públicas: evidências para o Brasil. Economia e Sociedade, Campinas, v. 22, n. 3, p. 765-790, Dec. 2013. Disponível em <http://www.scielo.br/scielo.php?script=sci_arttext\&pid=S010406182013000300007\&lng=en\&nrm=iso>. Acesso em 09 Jul. 2019. http://dx.doi.org/10.1590/S0104-06182013000300007.

\section{Credenciais da/os autora/es}

COSTA, Fabíola Marinho. Mestra e Doutora em Psicologia pela UFBA. Professora da Universidade Federal do Recôncavo da Bahia (UFRB) desde 2006. Tem experiência na área de Psicologia, com ênfase em Psicologia Organizacional e do Trabalho, atuando principalmente nos temas: comprometimento organizacional, comportamentos de voz e silêncio, diversidade e inclusão nas organizações, emoções e afetos no trabalho. E-mail: fabiolamcosta@ gmail.com

OLIVEIRA, Roberval Passos de. Mestre em Saúde Coletiva e Doutor em Saúde Pública pelo Instituto de Saúde Coletiva (ISC/UFBA). Atualmente, é Professor Associado do Centro de Ciências da Saúde (CCS) da Universidade Federal do Recôncavo da Bahia (UFRB). Coordena o Grupo de Pesquisa Saúde, Organizações e Trabalho (SORT). Tem experiência nas áreas de Psicologia Organizacional e

Educação, Psicologia e Interfaces, Volume 3, Dossiê Inclusão e Diversidade, p. 67-82, 2019. ISSN: 2594-5343. DOI: https://doi.org/10.37444/issn-2594-5343.v3i4.150 
do Trabalho e Saúde Coletiva, com ênfase em Formação e Trabalho em Saúde. E-mail: robervaloliveira@gmail.com

MEIRELES, Everson Cristiano de Abreu. Doutor em Psicologia / Avaliação Psicológica pela Universidade São Francisco. Mestre em Psicologia / Psicologia Social e do Trabalho pela Universidade de Brasília. Graduado em Psicologia (Bacharel e Psicólogo) também pela Universidade de Brasília. É professor adjunto do curso de Psicologia da Universidade Federal do Recôncavo da Bahia (UFRB) e membro fundador do Laboratório de Instrumentação e Avaliação Psicológica (LABIAP/UFRB). Atua como Chefe da Secretaria de Integração, Avaliação e Desenvolvimento Institucional (SIADI/Gabinete da Reitoria/UFRB, 02/2019-presente) e como pesquisador associado ao Observatório Nacional da Inclusão e Diversidade na Educação - DIVERSIFICA/UFRB. Desenvolve atividades de ensino, pesquisa e extensão no campo da avaliação de indivíduos, grupos e instituições, com ênfase em Métodos Quantitativos, Avaliação Psicológica, Psicometria, Construção e Validação de Medidas e Testes Psicológicos; Psicologia Social e Comportamento do Consumidor. Email:eversoncam@yahoo.com.br

SANTANA, Luciana Alaíde Alves. Mestra em Saúde Coletiva pelo Instituto de Saúde Coletiva da Universidade Federal da Bahia (2001) e Doutora em Ciências da Educação, na área de concentração Sociologia da Educação do Instituto de Educação da Universidade do Minho em Portugal (2017). Atua como Professora da Universidade Federal do Recôncavo da Bahia do curso de Bacharelado Interdisciplinar em Saúde, como Vice-Coordenadora do DIVERSIFICA - Observatório Nacional da Inclusão e Diversidade na Educação e como Coordenadora do Curso de Especialização em Inclusão e Diversidade na Educação. Na UFRB já ocupou os cargos de coordenadora do colegiado do curso de Bacharelado Interdisciplinar em Saúde, Chefe de Gabinete do Reitor e Pró-Reitora de Graduação. Na área de educação desenvolve estudos sobre diversidade e inclusão na educação, sucesso educativo de estudantes, formação em ciclos no ensino superior e organização curricular integrada de curso de Bacharelados Interdisciplinares. E-mail: lualaide@ufrb.edu.br

Endereço para correspondência: Roberval Passos de Oliveira. Universidade Federal do Recôncavo da Bahia. Avenida Carlos Amaral, 1015, Cajueiro, Santo Antônio de Jesus - Bahia. CEP: 44574490 Brasil. E-mail: robervaloliveira@gmail.com

Como citar este artigo (Formato ABNT): COSTA, Fabíola Marinho et al.. Diversidade entre docentes das instituições de educação superior brasileiras. Educação, Psicologia e Interfaces, v. 3, Dossiê Inclusão e Diversidade, p. 67-82, 2019. DOI: https://doi.org/10.374444/issn-2594-5343.v3i4.150

Recebido: 09/09/2019.

Aceito: 10/10/2019.

Educação, Psicologia e Interfaces, Volume 3, Dossiê Inclusão e Diversidade, p. 67-82, 2019. ISSN: 2594-5343. DOI: https://doi.org/10.37444/issn-2594-5343.v3i4.150 